\title{
Perinatal outcomes in pregnant women with heart disease: Hospital General León experience
}

\author{
Edgar Ruiz Treviñoํㅜ, Gabriela Tecayehuatl Delgado ${ }^{1}$, Junior Joel Araiza Navarro ${ }^{2 *}$
}

\author{
${ }^{1}$ Department of Gynecology and Obstetrics, General Hospital of León, Guanajuato, México \\ ${ }^{2}$ Deparment of Gynecology and Obstetrics, Centro Médico Naval, Postgraduate School in Naval Health, Coyoacán, \\ Mexico
}

Received: 05 December 2018

Accepted: 21 December 2018

\section{*Correspondence: \\ Dr. Junior Joel Araiza Navarro, \\ E-mail: joelara16@hotmail.com}

Copyright: () the author(s), publisher and licensee Medip Academy. This is an open-access article distributed under the terms of the Creative Commons Attribution Non-Commercial License, which permits unrestricted non-commercial use, distribution, and reproduction in any medium, provided the original work is properly cited.

\section{ABSTRACT}

Background: Pregnancies in patients with heart disease are often complicated. The prevalence in our country is at 0.1 to $4 \%$. An increase in the morbidity and mortality of pregnant patients with heart disease was observed, so it is recommended to evaluate the maternal risk with the WHO Classification. The objective of the study was to determine adverse outcomes; cardiac, obstetric and fetal/neonatal.

Methods: We retrospectively studied all pregnancies of women with heart disease that were presented on an outpatient basis in the period of 4 years at the General Hospital of León and maternal, obstetric and fetal/ neonatal outcomes were reviewed.

Results: In our study population, no maternal or fetal mortality was observed. Of 16 pregnancies of patients with heart disease were complicated by adverse cardiac events ( 2 of 16), obstetric (9 of 16), fetal/ neonatal (6 of 16). Hospitalization was required during the pregnancy of 11 patients. WHO class IV was the only group in which there were adverse cardiac events. 12 pregnancies were interrupted abdominally. Low fetal growth curve was observed in 6 of the 16 patients.

Conclusions: Pregnancies in patients with heart disease have a high risk of cardiac, obstetric and fetal / neonatal complications. Therefore, preconceptionally counseling and specialized multidisciplinary management should be offered to reduce perinatal morbidity and mortality.

Keywords: Adverse outcomes, Heart disease, Pregnancy

\section{INTRODUCTION}

With the successful repair of different congenital heart diseases in childhood, a large percentage of patients survive to adulthood. ${ }^{1}$ Part of these patients have as expectations to have children in the future. However, there is also a group of patients in which they do not know about heart disease and therefore this group is the one that is related to an increase in maternal mortality. ${ }^{2-4}$ Preconceptional counseling should be offered by a specialized multidisciplinary team to assess cardiac function and structural defects to all women with congenital heart disease who want pregnancy. ${ }^{5}$ Currently,
$0.2-4 \%$ of all pregnancies in industrialized, western countries are complicated by cardiovascular diseases. ${ }^{6,7}$ In the western world, congenital heart disease is the most frequent cardiovascular disease during pregnancy (75$82 \%$ ), with a predominance of shunts (20-65\%). ${ }^{8,9}$ Rheumatic valvular disease dominates in non-Western countries and comprises 56-89\% during pregnancy. Cardiomyopathies are rare, but they are serious causes of complications. ${ }^{10}$ Several scoring systems have been developed to try to stamina the maternal cardiovascular risk, as well as the contraindications for pregnancy. It is recommended to stage the maternal cardiovascular risk according to the modified classification of the World 
Health Organization (WHO) (Table 1 and 2). ${ }^{11}$ Pregnancy induces hemodynamic changes, which can be poorly tolerated in women with congenital heart defects. Although maternal mortality is reported very rarely, maternal and fetal/ neonatal complications are much more frequent numerically. ${ }^{12,13}$
The objective of this study was to determine adverse outcomes, which occur in pregnant women with known and unknown heart disease. We estimated the cardiac, obstetric and fetal / neonatal outcomes that occurred in patients of our hospital who attended on an outpatient basis.

Table 1: Modified classification of the World Health Organization of maternal cardiovascular risk and its application, modified by Thorne et al. ${ }^{11}$

\begin{tabular}{|l|l|}
\hline Risk class & $\begin{array}{l}\text { Risk of pregnancy according to disease } \\
\text { I }\end{array}$ \\
\hline II & $\begin{array}{l}\text { So increase in detectable risk of maternal mortality and no increase or slight increase in morbidity } \\
\text { Significantly increased risk of maternal mortality or serious morbidity. Guidance from a specialist is } \\
\text { required. If it is decided to continue the pregnancy, intensive cardiac and obstetric monitoring is needed } \\
\text { by specialists throughout the pregnancy, delivery and puerperium }\end{array}$ \\
III & $\begin{array}{l}\text { Extremely high risk of maternal mortality or serious morbidity; contraindicated pregnancy. If the } \\
\text { pregnancy takes place, its interruption should be assessed. If the pregnancy continues, attention according } \\
\text { to class III }\end{array}$ \\
\hline IV &
\end{tabular}

Table 2: Cardiovascular risk classification WHO, adapted from Thorne et al. ${ }^{11}$

\begin{tabular}{|c|c|}
\hline WHO I & WHO III \\
\hline $\begin{array}{l}\text { Not complicated, small or light. } \\
\text { - Pulmonary stenosis. } \\
\text { - Permeable Ductus arteriosus. } \\
\text { - Prolapse of the mitral valve. }\end{array}$ & Mechanical valve \\
\hline $\begin{array}{l}\text { Simple lesions repaired successfully (atrial or ventricular } \\
\text { septal defect, patent ductus arteriosus, abnormal pulmonary } \\
\text { venous drainage). }\end{array}$ & Systemic right ventricle. \\
\hline Ectopic auricular or ventricular heartbeat, isolated. & Circulation of Fontan. \\
\hline WHO II o III & Cyanotic heart disease (not repaired). \\
\hline WHO II (If otherwise good and there are no complications) & Another complex congenital heart disease. \\
\hline Atrial or ventricular septal defect not operated. & Aortic dilatation $40-45 \mathrm{~mm}$ in Marfan syndrome. \\
\hline Tetralogy of Fallot repaired. & $\begin{array}{l}\text { Aortic dilatation } 45-50 \mathrm{~mm} \text { in aortic disease associated } \\
\text { with bicuspid aortic valve. }\end{array}$ \\
\hline The majority of arrhythmias. & WHO IV (contraindicated pregnancy) \\
\hline WHO II-III (depending on the person) & Pulmonary arterial hypertension from any cause. \\
\hline Light left ventricular dysfunction. & $\begin{array}{l}\text { Severe systemic ventricular dysfunction (LVEF }<30 \% \text {, } \\
\text { NYHA III-IV). }\end{array}$ \\
\hline Hypertrophic cardiomyopathy. & $\begin{array}{l}\text { Previous peripartum cardiomyopathy with any residual } \\
\text { impairment of left ventricle function. }\end{array}$ \\
\hline $\begin{array}{l}\text { Valvular heart disease or tissue that is not considered WHO I } \\
\text { or IV. }\end{array}$ & Severe mitral stenosis, severe systemic aortic stenosis. \\
\hline $\begin{array}{l}\text { Marfan syndrome without aortic dilation. Aorta }<45 \mathrm{~mm} \text { in } \\
\text { aortic disease associated with bicuspid aortic valve. }\end{array}$ & $\begin{array}{l}\text { Marfan syndrome with dilated aorta }>45 \mathrm{~mm} \text {. } \\
\text { Aortic dilatation }>50 \mathrm{~mm} \text { in aortic disease associated } \\
\text { with bicuspid aortic valve. }\end{array}$ \\
\hline Coarctation repaired. & Severe native coarctation. \\
\hline
\end{tabular}

\section{METHODS}

A retrospective, cross-sectional, observational and analytical study was carried out. We studied all pregnancies with known and not known heart disease that visited the General De León Hospital on an outpatient basis. Censuses and records were reviewed during the period from March 2015 to August 2018, where interesting data was obtained. Informed consent was not obtained due to the retrospective and purely observational 
design of the study. The approval was acquired by the administrative council of the General Hospital of León. The following reference data were collected: from the mother, diagnosis of heart disease, previous surgical interventions, comorbidities, body mass index (BMI), smoking history, knowledge of heart disease. Maternal cardiovascular risk assessment was performed by classifying patients according to the modified World Health Organization (WHO). Data related to pregnancy, including obstetric history (Pregnancies previously or unsuccessfully achieved) were reported; age of conception; cardiac, obstetric and fetal / neonatal complications; hospitalizations during pregnancy; the method of termination of pregnancy. It was reported that a pregnancy was complicated when adverse cardiac, obstetric or fetal/neonatal events were observed. Here we describe cardiac complications such as cardiac death, clinical signs of heart failure (requiring hospitalization or cardiac intervention), symptomatic arrhythmia, thromboembolic complications, postpartum hemorrhagic complications $(>500 \mathrm{ml}$ at delivery and $>1000 \mathrm{ml}$ in caesarean section), preeclampsia (pregnancy-induced hypertension with $>0.3$ gr of proteinuria in the urine sample of 24 hours) (data of damage to target organ), gestational diabetes.

\section{Inclusion criteria}

- Fetal/neonatal complications that included mortality, preterm labor (delivery $<37$ weeks), small fetuses for gestational age (percentile <10) and intrauterine growth restriction (IUGR) (percentile <3).

\section{Exclusion criteria}

- Patients who did not collect all the previous variables.

Continuous variables are expressed as mean or median and categorical data as counts. The multivariate analysis was not performed due to the low number of adverse events.

\section{RESULTS}

During the period of 4 years. A total of 20 pregnancies diagnosed with heart disease were found and examined on an outpatient basis. Of which 3 were excluded because they did not have a file to gather information and 1 when they were currently in pregnancy and therefore did not have complete perinatal results. Of the 16 patients who met the variables: The age group in which more patients were found was between $19-22$ years. Of 16 patients, 10 were nulliparous, 12 of the 16 patients reached the end successfully. Of the 16 patients, abdominal via 12 and 4 were interrupted vaginally. In our study, valvular heart disease prevalence was observed in relation to our population with a total of 10 out of 16 , of which 3 had aortic stenosis. The short circuit cardiopathies were 5 of
16 and only one patient with peripartum cardiomyopathy. (Table 3).

Table 3: Cardiac injury.

\begin{tabular}{|c|c|}
\hline Subtype of heart disease. & No. \\
\hline Peripartum cardiomyopathy & 1 \\
\hline Rheumatic heart disease/mitral valve injury & 1 \\
\hline Aortic stenosis & 3 \\
\hline Pulmonary stenosis & 2 \\
\hline Prolapse of the mitral valve/mitral insufficiency & 1 \\
\hline Aortic insufficiency & 1 \\
\hline Bicuspid Aortic Valve & 2 \\
\hline Interauricular communication & 2 \\
\hline $\begin{array}{l}\text { Interventricular communication/common } \\
\text { arteriovenous trunk/severe pulmonary } \\
\text { hypertension }\end{array}$ & 1 \\
\hline $\begin{array}{l}\text { Ebstein's Disease/IAC/Foramen ovale } \\
\text { permeable }\end{array}$ & 1 \\
\hline Tetralogy of Fallot & 1 \\
\hline
\end{tabular}

It was observed that the majority of our patients (10 of 16), had a Body Mass Index greater than 25 (Table 4).

Table 4: Characteristics of the patients.

\begin{tabular}{|l|l|}
\hline Basal characteristics of the mother & No. \\
\hline Maternal age & $19-22$ years \\
\hline Body mass index (BMI) & \\
\hline Under weight & 1 \\
\hline Normal & 5 \\
\hline Overweight & 8 \\
\hline Obesity & 2 \\
\hline Modified class WHO & \\
\hline I & 0 \\
\hline II & 4 \\
\hline II-III & 3 \\
\hline III & 7 \\
\hline IV & 2 \\
\hline Diagnosis of heart disease & \\
\hline Known disease & 1 \\
\hline Unknown disease & 5 \\
\hline No surgical management & 9 \\
\hline Surgical repair & 2 \\
\hline Mechanical valve & 5 \\
\hline Smoking & 1 \\
\hline Comorbidities & 13 \\
\hline Do not & 2 \\
\hline Chronic hypertension & \\
\hline
\end{tabular}

\section{Cardiac events}

Cardiac events occurred in 2 of 10 patients, who experienced dyspnea and hemodynamic instability with progression to cardiac failure, which required interruption of pregnancy after stabilization (Table 5). 


\section{Obstetric events}

Of the 16 pregnant patients' obstetric complications were observed in 9 , where 4 patients had hypertensive disease of pregnancy, 4 prematurity and one patient presented obstetric hemorrhage, without the need for blood transfusion (Table 5).

\section{Fetal/neonatal events}

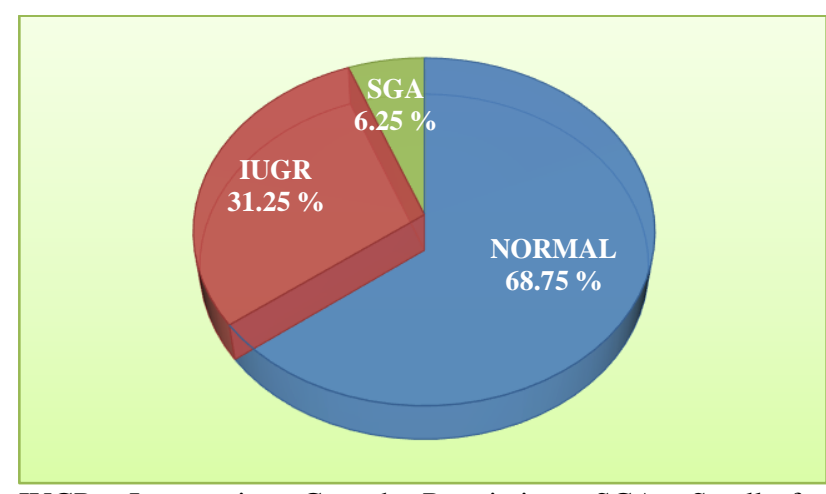

IUGR: Intrauterine Growth Restriction, SGA: Small for gestational age.

Figure 1: Fetal growth curve.

Fetal events were reported in 6 of 16 pregnancies. There was no fetal or neonatal mortality. The fetal growth curve of 6 pregnancies is striking. Of which 1 were below the percentile $<10$ and 5 below the percentile $<3$ (Table 5) and (Figures 1 and 2).

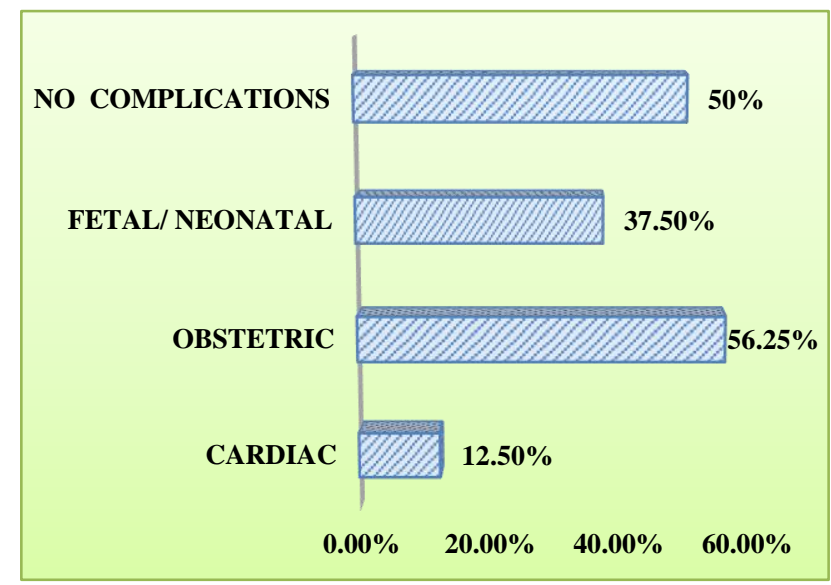

Figure 2: Results of events in pregnancy cardiopathy.

\section{Hospitalization during pregnancy}

Of all the pregnancies that took control in the General Hospital of León, 11 of 16 patients needed hospitalization. Of these only two patients were admitted to intensive care and 4 patients remained hospitalized for hypertensive disease of pregnancy; of which 1 was classified as gestational hypertension and 3 as preeclampsia with severity data. (Table 5).
Table 5: Adverse complications.

\begin{tabular}{|l|l|}
\hline Complications during pregnancy & No \\
\hline Cardiac complications & 2 \\
\hline Mortality & 0 \\
\hline Dyspnoea & 2 \\
\hline Heart failure & 2 \\
\hline Symptomatic cardiac arrhythmia & 0 \\
\hline Thromboembolic events & 0 \\
\hline Need for hospitalization & 11 \\
\hline Obstetric complications & 9 \\
\hline Induced hypertension during pregnancy & 1 \\
\hline Pre-eclampsia & 3 \\
\hline Gestational diabetes & 0 \\
\hline Obstetric hemorrhage & 1 \\
\hline Prematurity & 4 \\
\hline Fetal/ neonatal complications & 6 \\
\hline Mortality & 0 \\
\hline Small for gestational age & 1 \\
\hline Intrauterine growth restriction & 5 \\
\hline
\end{tabular}

\section{DISCUSSION}

\section{Cardiac events}

Only two pregnancies were complicated by cardiac events; presenting dyspnea, hemodynamic instability and progression to heart failure with the need to interrupt gestation. These cardiac events were only observed in patients in WHO group IV. (Peripartum cardiomyopathy and common arteriosus trunk / VSD / severe pulmonary hypertension) increasing the risk of mortality, which agrees with that reported in the international literature. ${ }^{14}$

\section{Obstetric events}

The main obstetric events were hypertensive diseases and Prematurity.

\section{Fetal/neonatal events}

In our study, no fetal or neonatal mortality was observed, however, increased morbidity due to prematurity and low weight for gestational age (6/16).

Data were collected retrospectively, including information and selection bias. In addition, the study was carried out in a single medical center; General Hospital of León. This prevents safe conclusions regarding the population and any result must be interpreted with caution. However, given that the prevalence of heart disease in our country is 0.1 to $4 \%$, our results provide information on the evolution and potential complications of pregnancy in this group of patients. In the literature there are different classifications that predict the risk of maternal complications in pregnant women with heart disease. The most used is the WHO modified risk classification, since it is the one that most correlates with maternal complications, however, there are other 
prognostic classifications such as CARPREG and ZAHARA, we rely on the WHO risk classification. ${ }^{15}$ Pregnancy occurs with various physiological changes, in which a woman without pathologies would have no major problem, in pregnant women with heart disease pregnancy can be harmful to both the mother and the fetus, this due to the hemodynamic changes of pregnancy, is appropriate preconceptional counseling and adequate assessment of the possible risks that pregnancy in conjunction with maternal heart disease would cause the fetus and the mother, in addition to heart disease that is not compatible with pregnancy and in this case contraindicated, some examples they are: Eisenmenger syndrome, cyanotic non-repaired heart disease and Marfan syndrome with aortic repercussions. ${ }^{16}$ There are not enough studies yet to establish guidelines in pregnant women with heart disease in order to reduce the morbidity and mortality of the mother and the fetus, at the moment it is important to identify this group of patients and categorize them by risk, taking a multidisciplinary prenatal control by of cardiology and maternal fetal medicine. ${ }^{16,17}$

\section{CONCLUSION}

Pregnancies in patients with heart disease have a high risk of cardiac, obstetric and fetal/ neonatal complications. Therefore, preconceptional counselling and specialized multidisciplinary management should be offered to reduce perinatal morbidity and mortality.

Funding: No funding sources

Conflict of interest: None declared

Ethical approval: The present study was approved by the Ethics and Local Research Committee, of the General Hospital of León, Guanajuato

\section{REFERENCES}

1. Swan L. Congenital heart disease in pregnancy. Best Pract Res Clin Obstet Gynaecol. 2014;28(4):495506.

2. Regitz-Zagrosek V, Roos-Hesselink JW, Bauersachs J, Blomström-Lundqvist C, Cifkova R, De Bonis M, et al. 2018 ESC Guidelines for the management of cardiovascular diseases during pregnancy. Europe Heart J. 2018;39(34):3165-241.

3. Huisman CM, Zwart JJ, Roos-Hesselink JW, Duvekot JJ, van Roosmalen J. Incidence and predictors of maternal cardiovascular mortality and severe morbidity in The Netherlands: a prospective cohort study. PLoS One. 2013;8(2):e56494.

4. Rao S, Ginns JN. Adult congenital heart disease and pregnancy. Semin Perinatol. 2014;38(5):260-72.

5. van der Bom T, Bouma BJ, Meijboom FJ, Zwinderman $\mathrm{AH}$, Mulder BJ. The prevalence of adult congenital heart disease, results from a systematic review and evidence-based calculation. Am Heart J. 2012;164(4):568-75.

6. Ntiloudi D, Zegkos T, Bazmpani MA, Parcharidou D, Panagiotidis T, Hadjimiltiades S, et al. Pregnacy outcome in women with congenital heart disease: A single-center experience. Hellenic $\mathrm{J}$ Cardiol. 2018;59(3):155-9.

7. López HC, Aguilar HE, Aguilar FD. Cardiopatía y embarazo. Ginecología y Obstetricia de México. 2006;74(03):153-7.

8. Khairy P, Ionescu-Ittu R, Mackie AS, Abrahamowicz M, Pilote L, Marelli AJ. Changing mortality in congenital heart disease. J Am Coll Cardiol. 2010;56(14):1149-57.

9. Hernández-Pacheco JA, Estrada-Altamirano A, Nares-Torices MÁ, Mendoza-Calderón SA, OrozcoMéndez H, Hernández-Muñoz VA, et al. Pronóstico materno y perinatal en mujeres embarazadas con cardiopatías congénitas con cortocircuito en el Instituto Nacional de Perinatología Isidro Espinosa de los Reyes. Perinatol Reprod Hum 2012;26(4): 137-46.

10. Marelli AJ, Ionescu-Ittu R, Mackie AS, Guo L, Dendukuri N, Kaouache M. Lifetime prevalence of congenital heart disease in the general population from 2000 to 2010. Circulat. 2014;130(9):749-56.

11. Ruys TP, Roos-Hesselink JW, Pijuan-Domènech A, Vasario E, Gaisin IR, Lung B et al. ROPAC investigators. Is a planned caesarean section in women with cardiac disease beneficial? Heart. 2015;101(7):530-6.

12. Drenthen W, Boersma E, Balci A, Moons P, RoosHesselink JW, Mulder BJ, et al. ZAHARA Investigators. Predictors of pregnancy complications in women with congenital heart disease. Eur Heart J. 2010;31(17):2124-32.

13. Drenthen W, Pieper PG, Roos-Hesselink JW, van Lottum WA, Voors AA, Mulder BJ et al, ZAHARA Investigartors. Outocome of pregnancy in women with congenital heart disease: a literature review. J Am Coll Cardiol. 2007;49(24):2303-11.

14. Regitz-Zagrosek V, Seeland U, Geibel-Zehender A, Gohlke-Bärwolf C, Kruck I, Schaefer C. Cardiovascular diseases in pregnancy. Dtsch Arztebl Int. 2011;108(16):267-73.

15. Maternal cardiopathy and pregnancy, Protocol, Clinic Barcelona, 2018.

16. Garnica-Camacho CE. Congenital heart disease in pregnant women: approach of the internist doctor. Med Int. 2016 ;32(4):436-45.

17. Diagnosis and Management of Cardiopathy in Pregnancy, Evidence and Recommendations, CENETEC, Master Catalog of Clinical Practice Guidelines, IMSS-538-11.

Cite this article as: Treviño ER, Delgado GT, Navarro JJA. Perinatal outcomes in pregnant women with heart disease: Hospital General León experience. Int J Reprod Contracept Obstet Gynecol 2019;8:54-8. 